\title{
Batch and continuous reactor studies for the adsorption of As(III) from wastewater using a hybrid biochar loaded with transition metal oxides: Kinetics and mass transfer analysis
}

\author{
Arijit Dutta Gupta ${ }^{1}$, Balendu Shekher Giri ${ }^{2}$, Eldon R Rene ${ }^{3}$, Preeti Chaturvedi ${ }^{2}$, \\ Mandavi Goswami ${ }^{1}$, Harinder Singh ${ }^{{ }^{\dagger}}$ \\ ${ }^{1}$ Department of Chemical Engineering, Motilal Nehru National Institute of Technology Allahabad, Prayagraj-211008, India \\ ${ }^{2}$ Aquatic Toxicology Laboratory, Environmental Toxicology Group, Council of Scientific and Industrial Research-Indian Institute of Toxicology Research \\ (CSIR-IITR), Vishvigyan Bhawan, Lucknow-226001, India \\ ${ }^{3}$ Department of Water Supply, Sanitation and Environmental Engineering, IHE Delft Institute for Water Education, The Netherlands
}

\begin{abstract}
As(III) presence in low concentration (1-5 mg/L) in water presents a challenging problem in its removal. In the present study, biochar prepared by the pyrolysis of mustard cake and loaded with Fe-Mn binary oxides through hydrothermal technique was used for adsorptive removal of $\mathrm{As}(\mathrm{III})$ from water in batch and continuous modes. The synthesised biochar exhibited mesoporous structures in the range of 2-50 nm (based on BET analysis). The maximum adsorption capacity $(95.7 \mathrm{mg} / \mathrm{g}$ ) obtained using biochar loaded with both Fe-Mn oxides was found to be 1.4 times higher than that of pristine biochar. The adsorption equilibria was best described by Freundlich isotherm (based on $R^{2}$ and $\chi^{2}$ ) suggesting that the As(III) adsorption was multilayered. The external mass transfer coefficients $\left(\beta_{L}=10^{-5} \mathrm{~cm}^{2} / \mathrm{s}\right)$ were observed to be higher than the film $\left(D_{f}=10^{-7}-10^{-9} \mathrm{~cm}^{2} / \mathrm{s}\right)$ and intraparticle $\left(D_{i}=10^{-9} \mathrm{~cm}^{2} / \mathrm{s}\right)$ diffusivities in batch mode. In column studies, Thomas model gave the best correlation coefficient $\left(R^{2}>0.95\right)$ and the adsorption was limited by external mass transfer. Kinetic rate constant decreased with increase in initial As(III) concentration and flow rate. The oxide loaded biochar exhibited reusability up to three times for As(III) removal.
\end{abstract}

Keywords: As(III) adsorption, Biochar, Fe-Mn oxides, Film Diffusion, Mass Transfer

\section{Introduction}

Arsenic contamination in groundwater is a serious problem being faced in countries such as India, Bangladesh, Nepal, China, Argentina, Taiwan and Mexico [1, 2]. Increased industrialization and natural processes such as weathering, erosion, volcanic eruptions, biological activities as well as other anthropogenic activities have resulted in tremendous increase in high levels of arsenic in groundwater. However elevated concentrations of arsenic are usually considered to be of geogenic in nature [3]. Long term exposure to As(III) in drinking water has increased the risk of skin, bladder, lungs and liver cancers in human body over the past decade [4]. According to WHO, the maximum concentration of As(III) in drinking water should not exceed $0.05 \mathrm{mg} / \mathrm{L}$ or $50 \mathrm{ppb}$.
However, in India, the minimum limit prescribed by CPCB should be below $25 \mathrm{ppb}$ [5].

Arsenic is said to prevail in the environment in the form of organic and inorganic forms with various oxidation states $(-3,0$, +3 and +5 ) with the inorganic arsenic being the most abundant [6]. In natural waters and shallow aquifers arsenic is present in the form of trivalent (As(III)) or pentavalent (As(V)) with As(III) being more poisonous [7]. Organic arsenic is said to undergo bio-transformations and methylation reactions which detoxifiy its effect [8]. $\mathrm{pH}$ and redox potential are the most governing factors that favour arsenic speciation. As(III) (arsenite) species prevails in reducing and anoxic waters whereas $\mathrm{As}(\mathrm{V})$ (arsenate) are generally detected in oxidising environment [9]. Pentavalent oxy anions such as $\mathrm{HAsO}_{4}{ }^{2-}, \mathrm{H}_{2} \mathrm{AsO}_{4}{ }^{-}$and $\mathrm{AsO}_{4}{ }^{3-}$ are stable at moderate or high
This is an Open Access article distributed under the terms of the Creative Commons Attribution Non-Commercial License (http://creativecommons.org/licenses/by-nc/3.0/) which permits unrestricted non-commercial use, distribution, and reproduction in any medium, provided the original work is properly cited.

Copyright (C) 2021 Korean Society of Environmental Engineers
Received August 03, 2020 Accepted October 30, 2020

${ }^{\dagger}$ Corresponding author

Email: harinderpdfb@gmail.com

Tel: +91-9936393111

ORCID: 0000-0002-1553-5396 
redox potential while trivalent oxy anions such as $\mathrm{H}_{2} \mathrm{AsO}_{3}{ }^{-}$are stable at lower redox potential [10]. In the neutral $\mathrm{pH}$ range (6.5-7.5) of most groundwater As(III) primarily occurs as neutral species $\left(\mathrm{H}_{3} \mathrm{AsO}_{3}{ }^{0}\right)$ due to which the conventional physico-chemical treatment methods are very difficult to remove this form of arsenic as compared to $\mathrm{As}(\mathrm{V})$ [11]. Different redox potential favours formation of various oxy anions via deprotonation of arsenious acids $\left(\mathrm{H}_{3} \mathrm{AsO}_{3}\right)$ and arsenic $\left(\mathrm{H}_{3} \mathrm{AsO}_{4}\right)$ [12]. In developing countries like India, Pakistan, Myanmar people cannot afford reverse osmosis or expensive water treatment processes and hence there is an increased attention towards finding economic and effective treatment methods.

Biochar is a carbon rich material produced through pyrolysis of biomass at high temperatures $\left(600-800^{\circ} \mathrm{C}\right)$ in an inert atmosphere [13]. Biochar has been widely used over the years for water treatment and remediation of soil due to its inherent properties such as high porosity, large surface area per unit volume and a good cation exchange capacity [14]. Biochar is usually produced from inexpensive, abundant and easily available biowastes derived from food and agricultural by-products [15]. Biochar from various sources like cotton stalk [16], peanut shell [17], sewage sludge [18], Japanese oak and perilla leaf [19, 20] and Cassia fistula [21] have been extensively used for arsenic removal from wastewater. However, the pristine biochar has been reported to show low adsorption capacity due to absence of active functional groups towards arsenic adsorption [22].

Thus in order to improve the adsorption capacities of the native (pristine) biochar, several modification techniques have been applied before or after pyrolysis [23]. Literature survey shows that biochar loaded with the transition metal oxides have proved to be good adsorbents for As(III) ions remediation from wastewater. $\mathrm{ZnCl}_{2}$ activated biochar from pig manure was reported to show an $\mathrm{As}(\mathrm{III})$ adsorption capacity of $27.7 \mathrm{mg} / \mathrm{g}$ for an initial As(III) concentration of $40 \mathrm{mg} / \mathrm{L}$ as reported by Xia et al. [24]. An adsorption capacity of $2.5 \mathrm{mg} / \mathrm{g}$ was exhibited by bismuth impregnated wheat straw biochar with $20 \mathrm{mg} / \mathrm{L}$ as the initial As(III) concentration as reported by Zhu et al. [25]. As(III) removal (100 mg/L) using Fe-Mn corn straw biochar composite was reported to show an adsorption capacity of $8.3 \mathrm{mg} / \mathrm{g}$ by Lin et al. [26]. A binary sorbent containing Fe-Mn oxides have been synthesised, exhibiting high efficiency in the removal of both arsenate and arsenite as reported by Qi et al. [3]. A high surface to volume ratio of Fe-Mn oxides renders it fast kinetics and significantly enhanced adsorption capacity as investigated by Luo et al. [22]. Arsenic removal using calcined $\mathrm{MnO}_{2}$ has been reported to show adsorption capacity of $2.3 \mathrm{mg} / \mathrm{g}$ by Jung et al. [27]. However, due to its low mechanical strength and ability to form aggregates at high pressures and flow rates, it cannot be used for fixed bed or other flow studies [28]. Thus in order to overcome such limitations, Fe-Mn oxides are immobilized by loading, coating or impregnating them over carriers or support media under an oxidative activation using $\mathrm{KMnO}_{4}$, ferrous chloride or epichlorohydrin [3, 29]. However, the above cited studies have used high initial As(III) concentration (> $15 \mathrm{mg} / \mathrm{L}$ ) which was quite easier to remove due to high mass transfer driving force.

Mustard oil industry is one of the huge agricultural based industries producing around 6.1 million metric tonnes/year mustard oil cakes. In the present study, biochar was derived from waste mustard cake and then loaded with Fe-Mn binary oxides via hydrothermal technique. Removal of low As(III) concentration from water is one of the challenging problem since it presents low mass transfer driving force. Since only a handful of literature deals with low initial As(III) concentration in water, the present study has been done in order to fill this research gap utilizing mustard cake biochar (agricultural waste) loaded with Fe-Mn binary oxides. The advantage of using Fe-Mn oxides as compared to other oxides such as $\mathrm{ZnCl}_{2}$ lies in its removal mechanism. The mechanism of arsenic adsorption using $\mathrm{ZnCl}_{2}$ takes place via ligand exchange while that of using binary Fe-Mn oxides consists of simultaneous oxidation and adsorption creating some synergistic effects. This necessitates the use of comparatively lesser amount of metal precursors. Moreover, $\mathrm{Zn}$ or other metal oxides have been reported to be more toxic than Fe and Mn [30]. In addition most of the literature deals with removal of $\mathrm{As}(\mathrm{V})$ which is easier than As(III) removal. In this study, batch and column experiments were conducted in order to study the efficiency of the loaded biochar towards arsenic removal from wastewater and its potentiality to be used at industrial scale. Various models for batch and column experiments were applied to study the mechanism and interaction of As(III) ions over the loaded biochar. In addition, empirical correlations have been developed to investigate the effect of mass transfer coefficients on As(III) concentration. Depending on these correlations, rate limiting step towards adsorption was proposed. Thus the present research is significant in two aspects: utilization of the biochar (or agricultural waste) and pollution mitigation.

\section{Materials and Methods}

\subsection{Chemical Reagents}

All the chemicals used in the study were of high purity (> 97\%) of AR grade without further purification. Ferric chloride hexahydrate $\left(\mathrm{FeCl}_{3} .6 \mathrm{H}_{2} \mathrm{O}\right)$, manganese chloride hexahydrate $\left(\mathrm{MnCl}_{2} \cdot 6 \mathrm{H}_{2} \mathrm{O}\right)$, sodium hydroxide $(\mathrm{NaOH})$, potassium iodate $\left(\mathrm{KIO}_{3}\right)$, rhodamine-B and hydrochloric acid $(\mathrm{HCl})$ were purchased from Merck India. The glass wares were rinsed with $1 \%$ potassium dichromate and $\mathrm{HCl}$ before use.

\subsection{Synthesis of Adsorbents}

Mustard cakes were received from a nearby mustard oil mill from Prayagraj district, India. The proximate analysis of mustard cake has been tabulated in Table S1. It was then grinded and sieved through 200 mesh screen. Dirt and suspended impurities were removed by washing the cakes thoroughly with distilled water. It was then treated with hexane to remove any residual oil. Pyrolysis was done in a pyrolyser under inert atmosphere at $750^{\circ} \mathrm{C}$ temperature. The pyrolysed biochar was activated using $10 \% \mathrm{HNO}_{3}$ solution. It was then subjected to drying at $100^{\circ} \mathrm{C}$ till complete dryness was achieved.

For loading of metal oxides, $100 \mathrm{~g}$ of the dried biochar obtained from the above steps was treated with an equimolar mixture (0.1M each) of $\mathrm{FeCl}_{3}$ and $\mathrm{MnCl}_{2}$ and by individual salts also. The ratio of the metal precursors (Fe-Mn) to the dried biochar 
was maintained around 0.03 (by mass). The resultant mixture was magnetically stirred for $4 \mathrm{~h}$ and then $\mathrm{NaOH}$ solution $(0.1$ $\mathrm{M}$ ) was added to the mixture in a drop wise manner till the $\mathrm{pH}$ of the mixture reached 10.0. Hydrothermal reaction was then carried out at $180^{\circ} \mathrm{C}$ for $16 \mathrm{~h}$. The product was cooled to room temperature, centrifuged followed by repeatedly washing with ethanol and distilled water till neutral $\mathrm{pH}$. The samples were then dried in a hot air oven at $80^{\circ} \mathrm{C}$ for $12 \mathrm{~h}$ and stored in desiccators for adsorption studies. The adsorbents were labelled as BC, BCM, BCF and BCFM for native, Mn loaded biochar, Fe loaded biochar and both Fe-Mn oxides loaded biochar respectively.

\subsection{Adsorbent Characterizations (FTIR, SEM, XRD and BET)}

The adsorbent samples were washed with acetone, dried and pulverised and then subjected to gold coating in a vacuum sputtering unit prior to SEM analysis. Surface morphologies were studied using a scanning electron microscope (SEM) (Zeiss Evo -50, Germany) under an accelerating voltage of $10 \mathrm{kV}$. Fourier Transform Infrared Spectroscopy (FTIR) analysis was carried out using PerkinElmer Spectrum Version 10.03.06, USA. X-Ray Diffraction (XRD) analysis was done with a X-Ray diffractometer (Rigaku Smart Lab 3KW, USA) under standard operating conditions $\left(2 \theta=5^{\circ}\right.$ $70^{\circ}$ with a step size of $0.02^{\circ}$ and $\mathrm{Cu}-\mathrm{K} \alpha$ radiation). BET surface area analysis was carried out using Smart Sorb 92/93 surface area analyser in the presence of liquid nitrogen.

\subsection{Batch Adsorption Experiment}

Batch experiments were carried out with $1 \mathrm{mg} / \mathrm{L}$ as an initial As(III) concentration. Since only few studies deal with low initial As(III) concentration. $1000 \mathrm{mg} / \mathrm{L}$ of As(III) stock solution was prepared by dissolving $0.1735 \mathrm{~g}$ of $\mathrm{NaAsO}_{2}$ in $100 \mathrm{~mL}$ of distilled water. The $\mathrm{pH}$ of the adsorbate was varied from 2.0 to 10.0 using 0.1 $\mathrm{M} \mathrm{HCl}$ and $\mathrm{NaOH}$ solution to study influence of $\mathrm{pH}$ on the adsorption capacity. Presence of $\mathrm{As}(\mathrm{III})$ in solution was determined by Rhodamine-B oxidation method as reported by Pillai et al. [31]. The limit of detection was $0.03 \mathrm{mg} / \mathrm{L}$. The percent $\mathrm{As}(\mathrm{III})$ removal was calculated from Eq. (1):

$$
\% \text { Removal }=\frac{\left(C_{i}-C_{e}\right)}{C_{i}} \times 100
$$

The equilibrium sorption capacity was calculated using Eq. (2):

$$
q_{e}=\frac{\left(C_{i}-C_{e}\right)}{m} \times V
$$

where $q_{e}$ is the adsorption capacity at equilibrium $(\mathrm{mg} / \mathrm{g}), C_{i}$ and $C_{e}$ are the initial and equilibrium adsorbate concentration $(m g / L), m$ is the adsorbate mass $(g), V$ is the volume of the solution $(L)$.

\subsubsection{Isotherm modeling}

The sorption isotherm of As(III) ions over the native and loaded biochar was studied by batch adsorption experiments in $100 \mathrm{~mL}$ of adsorbate containing $1 \mathrm{mg} / \mathrm{L}$ of As(III) with adsorbent mass ranging from 0.01 to $0.1 \mathrm{~g}$ and subsequently shaking them in a temperature controlled incubator cum shaker (Remi CIS-24 PLUS TFT, India) at $25^{\circ} \mathrm{C}$ and $200 \mathrm{rpm}$ to achieve equilibrium. The adsorbate $\mathrm{pH}$ was maintained neutral $(7.0 \pm 0.2)$. The resultant mixture after attainment of equilibrium was filtered through Whatman filter paper (12 $\mu \mathrm{m}$ pore size) and then analysed for As(III) ions using UV-spectrophotometer (Motras Scientific UV PLUS). The governing equations for Langmuir, Freundlich, Temkin and Dubinin-Radushkevich (D-R) isotherms have been provided in the Supplementary materials.

\subsubsection{Kinetic modeling}

In order to study the kinetics of adsorption, batch adsorption was carried out with an initial As(III) ions concentration of $1 \mathrm{mg} / \mathrm{L}$ at neutral $\mathrm{pH}(7.0 \pm 0.2)$ under a constant temperature of $25^{\circ} \mathrm{C}$. The adsorbate samples were withdrawn at regular intervals of $30 \mathrm{~min}, 1 \mathrm{~h}, 1.5 \mathrm{~h}, 2 \mathrm{~h}$ and $4 \mathrm{~h}$, followed by filtration and then analysed for As(III) ions. Pseudo first order, pseudo second order, intraparticle diffusion and Elovich kinetic models have been used to analyse the kinetics of adsorption in the present study. Pseudo first order kinetic model equation is shown in Eq. (3):

$$
\ln \left(q_{e}-q_{t}\right)=\ln q_{e}-k_{1} t
$$

Pseudo second order kinetic model equation is shown in Eq. (4):

$$
\frac{t}{q_{t}}=\frac{1}{k_{2} q_{e}^{2}}+\frac{t}{q_{e}}
$$

where $q_{e}$ and $q_{t}$ are the equilibrium and instantaneous adsorption capacities in $\mathrm{mg} / \mathrm{g}, k_{1}\left(\mathrm{~min}^{-1}\right)$ and $k_{2}\left(g(\mathrm{mg} \mathrm{min})^{-}\right)^{1}$ are pseudo first and second order rate constants, respectively and $t$ is time in min.

Eq. (5) shows the model equation for Intraparticle diffusion:

$$
q_{t}=K_{i d} t^{1 / 2}+I
$$

where $K_{i d}$ is the intraparticle rate constant in $\mathrm{mg} / \mathrm{g} \cdot \mathrm{min}^{1 / 2}$ and $I$ is the thickness of the adsorbate film formed on the surface of the adsorbent during intraparticle diffusion in $\mathrm{mg} / \mathrm{g}$.

Elovich kinetic model equation is shown in Eq. (6):

$$
q_{t}=\frac{1}{\beta} \ln (\alpha \beta)+\frac{1}{\beta} \ln t
$$

where $\alpha$ (mg/g.min) and $\beta$ ( $g / m g$ ) are the adsorption and desorption constants.

\subsubsection{Diffusion and mass transfer analysis}

Boyd mass transfer model was studied to make a clear distinction between the film and intraparticle diffusion. Eq. (7) shows Boyd mass transfer model:

$$
\begin{gathered}
F=1-\frac{6}{\pi^{2}} \exp (-B t) \\
F=\frac{q_{t}}{q_{e}}
\end{gathered}
$$


where $F$ is the fraction of the adsorbate adsorbed at any instant of time $t$ calculated from Eq. (8) and $B t$ is considered as the mathematical function of $F$. The above expression can be rewritten as in the form of Eq. (9):

$$
B t=[-0.4977-\ln (1-F)]
$$

In order for film diffusion to be the rate-limiting step, the linear plot of $[-0.4977-\ln (1-F)]$ versus $t$ should not pass through origin. Effective film diffusivity $\left(D_{f}\right)$ in $\mathrm{cm}^{2} / \mathrm{s}$ is calculated using Eq. (10):

$$
B=\frac{\pi^{2} D_{f}}{r^{2}}
$$

where $r$ is the particle radius in $\mathrm{cm}$.

McKay et al. [32] mass transfer model is used to analyse the effect of mass transfer resistance on the rate of adsorption. The mass transfer coefficient $\beta_{L}$ in $\mathrm{cm} / \mathrm{s}$ of $\mathrm{As}$ (III) at the adsorbate-adsorbent interface can be determined by Eq. (11):

$$
\begin{gathered}
\ln \left(\frac{C}{c_{o}}-\frac{1}{1+m K}\right)=\ln \left(\frac{m K}{1+m K}\right)-\left(\frac{1+m K}{m K}\right) \beta_{L} A t \\
K=q_{m} \times k_{L}
\end{gathered}
$$

where $q_{m}$ is the maximum adsorption capacity in mg/g and $k_{L}$ is the Langmuir constant in $\mathrm{L} / \mathrm{mg}$. $\beta_{L}$ is calculated from the slope of the linear plot of $\ln \left(\left(C / C_{o}\right)-1 /\left(1+m k_{\mathrm{L}}\right)\right)$ vs time $(t)$.

\subsubsection{Adsorption thermodynamics}

The thermodynamic parameters such as standard Gibb's free energy change $\left(\Delta G^{\circ}\right)$, change in enthalpy $(\Delta H)$ and entropy change $(\Delta S)$ have been determined using the relation in Eqs. (13), (14) and (15):

$$
\begin{gathered}
\Delta G^{\circ}=-R T \ln K_{c} \\
K_{c}=\frac{q_{e}}{C_{e}} \\
\ln K_{c}=\frac{\Delta S}{R}+\frac{\Delta H}{R T}
\end{gathered}
$$

where $R$ is the gas constant $\left(R=8.314 \mathrm{~J} \mathrm{~mol}^{1} K^{1}\right), K_{c}$ is the equilibrium constant and $T$ is the absolute temperature in $K$. The values of $\Delta H$ and $\Delta S$ can be obtained respectively from the intercept and slope values of $\ln K_{c}$ versus (1/T) plot.

\subsection{Continuous Column Study}

Fixed bed experiments were carried out using a borosilicate glass column (internal diameter of $2.5 \mathrm{~cm}$ and $60 \mathrm{~cm}$ length) packed with the adsorbent (with bed height varying from 10 to $30 \mathrm{~cm}$ ) supported on gravels which acts as an inert material. Glass wool was used as a packing material for the adsorbent. Influent flow rate was controlled using a peristaltic pump. The influent As(III) bearing solution was fed to the column at a flow rate of $7.5 \mathrm{~mL} / \mathrm{min}$ by varying the bed depths at 10,20 and $30 \mathrm{~cm}$.

\subsubsection{Analysis and calculations of column experiments}

The movement of effluent adsorptive concentration at the outlet of the fixed bed adsorber is expressed in terms of breakthrough curve. The total volume of As(III) ions treated between breakthrough and column exhaustion $\left(V_{S}\right)$ was determined using Eq. (16):

$$
V_{S}=Q t_{S}
$$

where $Q$ is the volumetric flow rate of the influent in $\mathrm{mL} / \mathrm{min}$ and $t_{S}$ is the total flow time till column exhaustion in min. The total quantity of As(III) adsorbed $\left(q_{t o t}\right)$ can be determined by calculating the area under the breakthrough curve which is shown Eq. (17):

$$
q_{\text {tot }}=\frac{Q A}{1000}=\frac{Q}{1000} \int_{t=0}^{t=t_{t o t}} C_{s} \cdot d t
$$

where $C_{s}$ is the concentration of $\mathrm{As}(\mathrm{III})$ adsorbed $A$ is the column cross-sectional area $\left(\mathrm{m}^{2}\right)$. The total quantity of As(III) in the influent $(X)$ in $\mathrm{mg}$ is evaluated from Eq. (18):

$$
X=\frac{C_{o} Q t}{1000}
$$

where $C_{o}$ is the initial As(III) concentration in $m g / L$. Column performance can be determined from the removal percentage of As(III) using Eq. (19):

$$
\% \text { As }(I I I) \text { removal }=\frac{q_{\text {tot }}}{X} \times 100
$$

where $X$ is the total quantity of $\mathrm{As}(\mathrm{III})$ ions in influent in $\mathrm{mg}$.

\subsubsection{Breakthrough curve modelling}

Design of a full scale fixed bed adsorption columns requires collection of data obtained from the laboratory scale column through the analysis of breakthrough curves at different flow rates, bed heights and initial As(III) ions concentration [33]. Dynamics of the fixed bed columns are expressed in terms of their kinetic models. They provide essential design parameters which are necessary for column scale-up [34]. In the present study, breakthrough curve modelling was studied using Adams-Bohart model, Bed Depth Service Time (BDST) model and Thomas model. The governing equations for these models have been provided in the Supplementary materials.

\subsubsection{Mass transfer analysis}

The mass transfer coefficient $\left(K_{c}\right)$ in a fixed bed adsorption is affected by the type of flow within a fixed bed. It can be calculated using Eq. (20):

$$
\begin{gathered}
K_{c}=\frac{F}{\delta} \times \int_{C_{b}}^{C} \frac{d C}{C-C_{e}} \\
\delta=\frac{L \times\left(V_{S}-V_{b}\right)}{V_{b}+f \times\left(V_{S}-V_{b}\right)} \\
f=\int_{0}^{1}\left(1-\frac{C}{C_{e}}\right) \cdot d\left(\frac{V-V_{b}}{V_{S}-V_{b}}\right)
\end{gathered}
$$


where $F$ is the mass flux in $\mathrm{kg} \cdot \mathrm{m} / \mathrm{s}^{2}, V$ is the total volume of As(III) solution fed to the column and $V_{b}$ is the breakthrough volume.

\subsection{Regeneration and Reuse of the Adsorbents}

In order to determine the reusability of the As(III) loaded BCFM adsorbent, regeneration was investigated with $10 \% \mathrm{NaOH}$ solution in 5 consecutive adsorption-desorption cycles. Here the word 'cycle' refers to the number of adsorption-desorption experimental runs performed with the same batch of adsorbent. The arsenite loaded BCFM was added to $10 \% \mathrm{NaOH}$ solution (100 mL) followed by stirring at room temperature for $4 \mathrm{~h}$. After washing and drying (till complete dryness) it was used for the next adsorption-desorption cycle.

\section{Results and Discussions}

\subsection{Adsorbent Characterizations}

The FTIR spectra of the native and oxide loaded biochar have been presented in Fig. 1(a). Both native and loaded biochar exhibited peak at $3,450 \mathrm{~cm}^{-1}$ which was attributed to the bending and stretching vibrations of hydroxyl groups [35]. A small shoulder peak at 2,200 $\mathrm{cm}^{-1}$ was seen in the pristine biochar which completely disappeared after loading of oxides. The pristine biochar exhibited a peak at $1505 \mathrm{~cm}^{-1}$ which was attributed to the carbonyl groups present in the sample. However, this peak was attenuated in BCFM, BCF and BCM adsorbents suggesting successful loading of the oxides into the biochar [26]. Another shoulder peak at $1,630 \mathrm{~cm}^{-1}$ was seen in the BC sample which indicated deformation of water molecule indicating physisorption of water [36]. Peak at $1,730 \mathrm{~cm}^{-1}$ in the $\mathrm{BC}$ adsorbent was attributed to the presence of non-ionic esters or carboxylic acid groups (-COOCH$/ 3 /-\mathrm{COOH})$ [20]. However, this peak was seen to have its intensity reduced in the loaded biochar samples. A peak at $515 \mathrm{~cm}^{-1}$ in the BCM adsorbent can be ascribed to vibrations of $\mathrm{Mn}-\mathrm{O}$ bonds [37]. The peak at 760 $\mathrm{cm}^{-1}$ was seen in the BCF sample which was attributed to the Fe-O vibrations [38]. However, these peaks were observed to be apparently shifted to $495 \mathrm{~cm}^{-1}$ in the BCFM adsorbent which showed that the band strength of the $\mathrm{Fe}-\mathrm{O}$ was reduced due to the presence of co-existing Mn-oxide [39].

The XRD patterns of the adsorbents have been shown in Fig. 1(b). The pristine biochar sample exhibited characteristic crystalline peak at $2 \theta=26^{\circ}$. However, the XRD patterns of the metal oxide loaded biochar indicated the absence of any such apparent crystalline peaks thus showing that both Fe and Mn oxides were added in the amorphous regions which were responsible for high adsorption capacity. The peak at $2 \theta=29^{\circ}$ in the native biochar (BC) indicated the formation of graphite during pyrolysis as reported by the Zhai et al. [40] with bamboo biochar. The presence of amorphous Fe-oxide in the BCFM and BCF adsorbent was confirmed by the peak at $2 \theta=30^{\circ}$ and $50^{\circ}$ [41]. Moreover, the BCFM adsorbent did not show any sharp peak between $2 \theta=40^{\circ}$ to $65^{\circ}$ which indicated that the formation of crystalline Fe-oxide was inhibited due to the presence on co-existing Mn-oxide [42]. The XRD pattern of the BCFM sample showed that Fe-Mn peaks contained three phases: $\mathrm{FeO}_{0.331} \mathrm{MnO}_{0.669}\left(2 \theta=35^{\circ}\right), \mathrm{Fe}_{0.25} \mathrm{Mn}_{1.4} \mathrm{C}_{0.6}\left(2 \theta=38.5^{\circ}\right)$ and $\mathrm{Fe}_{2.7} \mathrm{Mn}_{3} \mathrm{C}$ $\left(2 \theta=46.5^{\circ}\right)[43]$. Thus, it can be inferred that the oxide loaded biochar did not show any characteristic crystalline peak which was responsible for their high adsorption capacity than that of the pristine biochar.

The SEM micrographs of the native and loaded biochar adsorbents have been presented in Fig. S1. It can be clearly observed that the loaded biochar sample has more number of particles present in their pores. This may be hypothesised that the loading of Fe-Mn oxides on the biochar was successful. Further, the elemental composition (C, O, Fe and $\mathrm{Mn}$ ) was detected by EDX analysis. The native biochar exhibited two peaks of carbon (80.23\%) and oxygen (19.67\%). The EDX spectra of the oxide loaded biochar showed two obvious peaks. The elemental composition of both $\mathrm{C}$ and $\mathrm{O}$ accounted for around $81 \%$ and the remaining (19\%) corresponding to the loading of Fe-Mn binary oxides (Table S2). This showed the successful loading of the oxides on the biochar. This was further confirmed by BET surface area analysis. It was observed that the BET curves for the loaded biochar were not completely closed. This suggested that the loading of metal
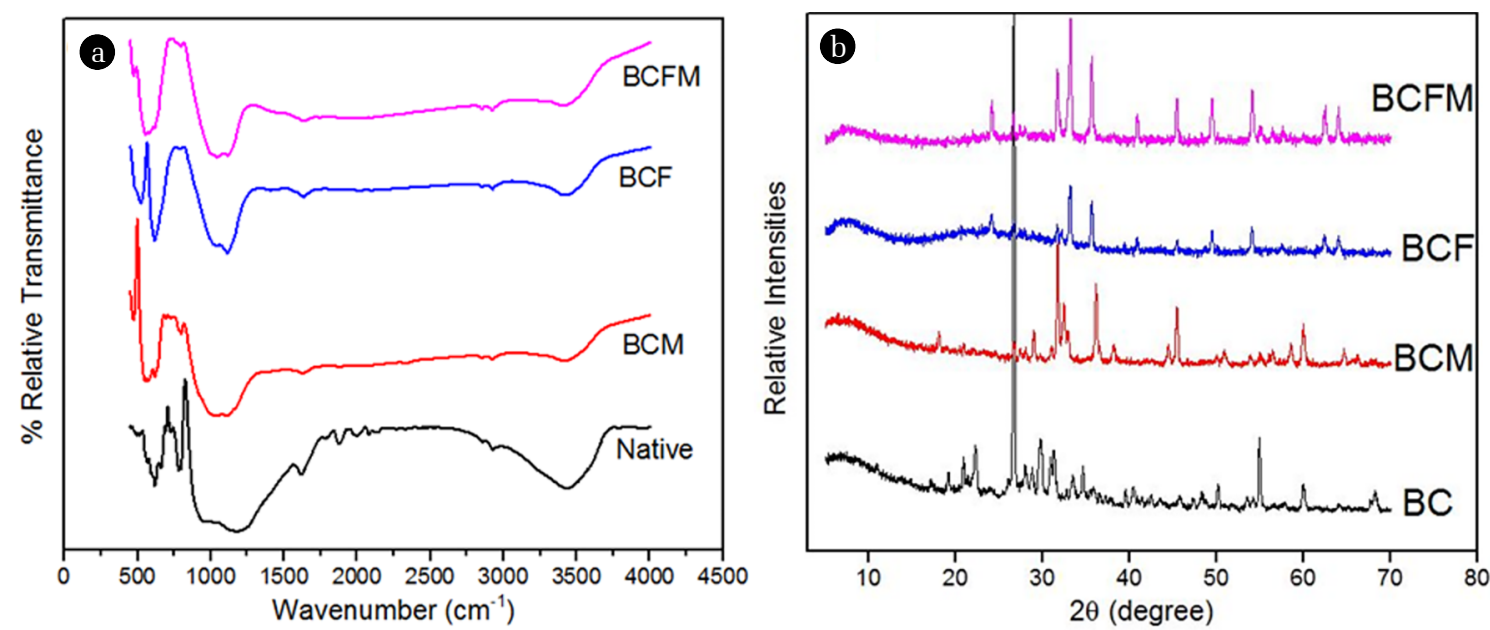

Fig. 1. (a) FTIR spectra; (b) XRD patterns of the native and oxide loaded biochar adsorbents. 
oxides changed the porous structures of the native biochar and were too complex to desorb $\mathrm{N}_{2}$ completely. The values for BET surface area, pore volume and pore diameter of the native biochar were observed to be higher than that of the metal oxides loaded biochar (Table S3). This showed the porous structure of the loaded biochars might have been partially filled with the particles of metal oxides. Moreover, the pore diameter distribution of BCFM $(2.72$ $\mathrm{nm}), \mathrm{BCF}(2.85 \mathrm{~nm}), \mathrm{BCM}(2.88 \mathrm{~nm})$ and BC $(3.54 \mathrm{~nm})$ showed that the synthesised biochar exhibited mesoporous structures in the range of 2-50 $\mathrm{nm}$.

\subsection{Batch Adsorption Studies}

\subsubsection{Effect of adsorbate $\mathrm{pH}$}

It was evident from Fig. S2 that the maximum adsorption capacity was obtained at neutral $\mathrm{pH}$ for both native and oxide loaded biochar. In the $\mathrm{pH}$ range of $4.0-8.0$, the dominating As(III) species are $\mathrm{H}_{3} \mathrm{AsO}_{3}$ and $\mathrm{H}_{2} \mathrm{AsO}_{3}^{-}$[43]. At neutral $\mathrm{pH}$ environment, $\mathrm{H}_{3} \mathrm{AsO}_{3}$ dominates while on further increasing the $\mathrm{pH}$ value, they are reduced to negatively charged ions. As the surface of the adsorbent is positively charged below $\mathrm{pH}_{\mathrm{PZC}}(=9.8)$ (Fig. S2), electrostatic forces of attraction between the negatively charged arsenite species and positively charged adsorbent's surface can adsorb As(III) ions to a greater extent. On further increasing the $\mathrm{pH}$ above 9.0, the presence of repulsive forces between the negatively charged adsorbent's surface and the negatively charged species $\left(\mathrm{H}_{2} \mathrm{AsO}_{3}{ }^{-}\right.$and $\mathrm{H}_{2} \mathrm{AsO}_{3}{ }^{2-}$ ), resulted in decrease in the adsorption capacity by around $25-30 \%$ [44]. Moreover at high $\mathrm{pH}$ value, the surface of the oxide loaded adsorbents (BCFM, BCF and BCM) became more electronegative which may be another reason for decrease in As(III) sorption capacity at basic $\mathrm{pH}$ reported by the authors Qi et al. [3].

\subsubsection{Isotherm modeling}

Adsorption equilibrium was described by the four isotherm plots (Langmuir, Freundlich, Temkin and D-R isotherms) which have been shown in Fig. S3 and the isotherm parameters have been tabulated in Table 1. The experimental adsorption capacities were 42.15, 36.24, 30.57 and $11.14 \mathrm{mg} / \mathrm{g}$ for BCFM, BCF, BCM and BC respectively. The obtained $q_{m}$ values were $95.76,83.25,74.66,30.17$ $\mathrm{mg} / \mathrm{g}$. Biochar loaded with both Fe and Mn oxides (BCFM) exhibited maximum adsorption capacities at constant temperature. The maximum $k_{L}(0.28 \mathrm{~L} / \mathrm{mg})$ and $k_{F}(38.91 \mathrm{mg} / \mathrm{g})$ values for the BCFM adsorbent further supported the fact. The separation factor values $\left(R_{L}\right)$ indicated that the adsorption of As(III) ions over native and oxide loaded biochar was favourable. Lower value of BCFM further indicated its relative ease towards As(III) adsorption from aqueous solution.

The higher $R^{2}$ values $\left(R^{2}>0.96\right)$ obtained from Freundlich isotherm model clearly indicated their better fitness over the Langmuir isotherm $\left(R^{2}>0.96\right)$. This showed that multilayered (heterogeneous) adsorption as the favourable mechanism towards As(III) removal. The $K_{F}$ values obtained from this isotherm model ranged between $7.1-39 \mathrm{~L} / \mathrm{mg}$ with the BCFM adsorbent showing the maximum $K_{F}$ value $(38.9 \mathrm{~L} / \mathrm{mg})$. The $n$ values reflected the degree of heterogeneity and intensity of the adsorbent's surface with As(III) ions. The $n$ values obtained were greater than 1 showing favourable and chemical nature of adsorption [45].
The obtained $A_{T}$ value was observed to be maximum (10.47 $L / g$ ) for BCFM adsorbent which suggested that the binding tendency of As(III) ions using BCFM was highest. The $b_{T}$ values almost showed a similar values for BCFM $(0.52 \mathrm{~kJ} / \mathrm{mol})$, BCF $(0.53 \mathrm{~kJ} / \mathrm{mol})$ and BCM $(0.53 \mathrm{~kJ} / \mathrm{mol})$ adsorbents demonstrating less variation in the heat of adsorption for the oxide loaded biochar adsorbents while the pristine biochar (BC) showed maximum value of $b_{T}(0.97 \mathrm{~kJ} / \mathrm{mol})$ which indicated maximum energy assimilation [46].

The $E$ value (from the D-R isotherm) was observed to be maximum for BCFM adsorbent $(0.92 \mathrm{~kJ} / \mathrm{mol})$ indicating its good affinity towards As(III) ions adsorption while the native biochar (BC) exhibited minimum $E$ value $(0.45 \mathrm{~kJ} / \mathrm{mol})$ indicating its poor adsorption affinity. The $E$ values were significantly less than $8.0-16.0 \mathrm{~kJ} / \mathrm{mol}$ which indicated adsorption of As(III) ions using the native and oxide loaded biochar took place through weak Van der Walls forces of attraction [46].

The $\chi^{2}$ values were used to check the best fit isotherm model with the experimental vales. A lower value of $\chi^{2}$ indicated its goodness of fit with the experimentally obtained data. Thus from the values of $R^{2}$ and $\chi^{2}$, it can be inferred that the Freundlich isotherm model best described the adsorption equilibria suggesting that the As(III) adsorption mechanism was multilayered and the sorbate molecules were held by weak Van der Walls forces irrespective of the biochar [40].

\subsubsection{Kinetic modeling}

Four kinetic models (pseudo first order, pseudo second order, intraparticle diffusion and Elovich kinetic models) were used to study the dependence of adsorption capacity of As(III) ions with time. The kinetic plots have been shown in Fig. S4 and the parameters have been shown in Table 1. The pseudo first order rate constant was found to be $k_{1}=0.022 \mathrm{~min}^{-1}$. The difference between the theoretically obtained adsorption capacity obtained from this model and the experimentally obtained adsorption capacity at the same temperature was significantly high. This suggested that pseudo first order kinetic model did not give a good correlation for As(III) adsorption. The second order rate constant was found to be $k_{2}=1.4 \times 10^{-4} \mathrm{~g}(\mathrm{mg} \cdot \mathrm{min})^{-1}$. The value of initial rate constant $\left(h=k_{2} \cdot q_{e}{ }^{2}\right)$ was obtained as 0.71 $\mathrm{mg} / \mathrm{g}$.min which was quite higher than the value of $k_{2}$. This showed that the rate of As(III) adsorption was significantly rapid at the initial stage of adsorption and the adsorption mechanism is predominantly chemisorption [46]. Further, the experimentally obtained $q_{e}$ value almost approached the theoretically obtained value $(42.16 \mathrm{mg} / \mathrm{g})$ at the same temperature showing its goodness of fit. Thus pseudo second order kinetic model showed a good correlation with the experimental data.

From the intraparticle diffusion plots (Fig. S4) it can be observed that the plot exhibited some degree of non-linearity and hence its effect can be ascertained. The initial portion of the curve shows a curved portion with a steeper slope which may be attributed to the presence of film or liquid boundary layer and subsequently, the slope of the curve decreased. This in turn, signified intraparticle diffusion [47]. Moreover, the intraparticle diffusion plot was not observed to pass through origin, which further confirmed the possibility of film diffusion taking place besides intra- 
Table 1. Estimated Isotherm Parameters for As(III) Adsorption using Native and Oxide Loaded Biochar

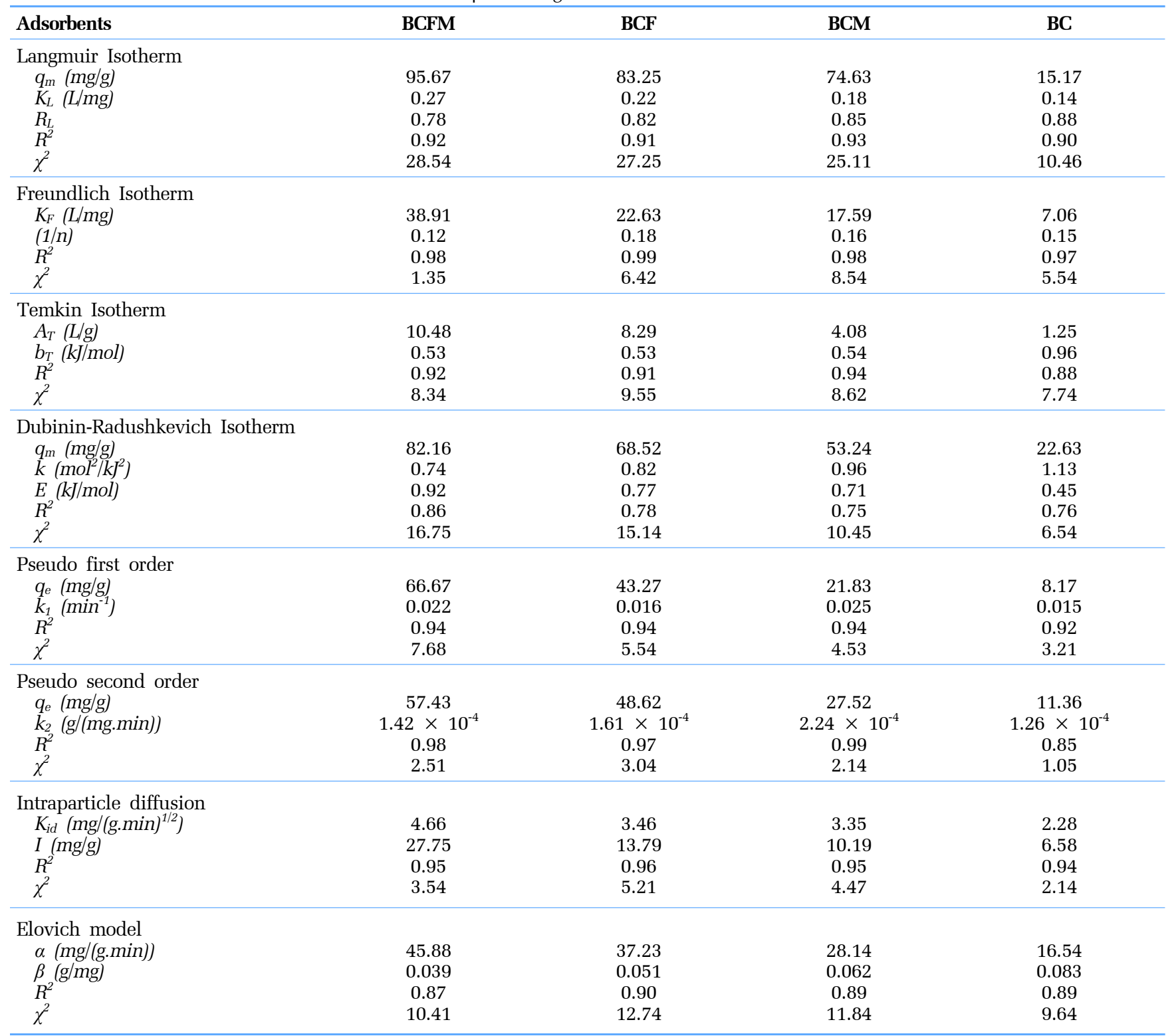

particle diffusion. In order to have a clear picture of the exact sorption mechanism, diffusion and mass transfer models have been analysed.

\subsubsection{Diffusion and mass transfer analysis}

As the intraparticle diffusion plots did not pass through origin giving an indication of film diffusion. The effective intraparticle diffusion coefficient $\left(D_{i}\right)$ has been calculated from Eq. (23):

$$
D_{i}=0.03 \frac{r^{2}}{t_{1 / 2}}
$$

where $t_{1 / 2}$ is represents half time adsorption. According to the researchers Singh and Pant [48], for intraparticle diffusion to be the rate controlling process, the $D_{i}$ values should lie between $10^{-5}$ to $10^{-13} \mathrm{~cm}^{2} / \mathrm{s}$. Thus in the present research, the values were in the range of $10^{-9} \mathrm{~cm}^{2} / \mathrm{s}$ which indicated some influence of intraparticle diffusion on As(III) adsorption as shown in Fig. 2(a). The empirical correlations between $D_{i}$ and $C_{o}$ based on the linearity of the plots are represented in Eqs. (24) - (27):

$$
\begin{array}{ll}
D_{i}=1.72 C_{o}^{-0.55} & \text { for BCFM } \\
D_{i}=1.48 C_{o}^{-0.61} & \text { for BCF } \\
D_{i}=1.33 C_{o}^{-1.37} & \text { for BCM }
\end{array}
$$



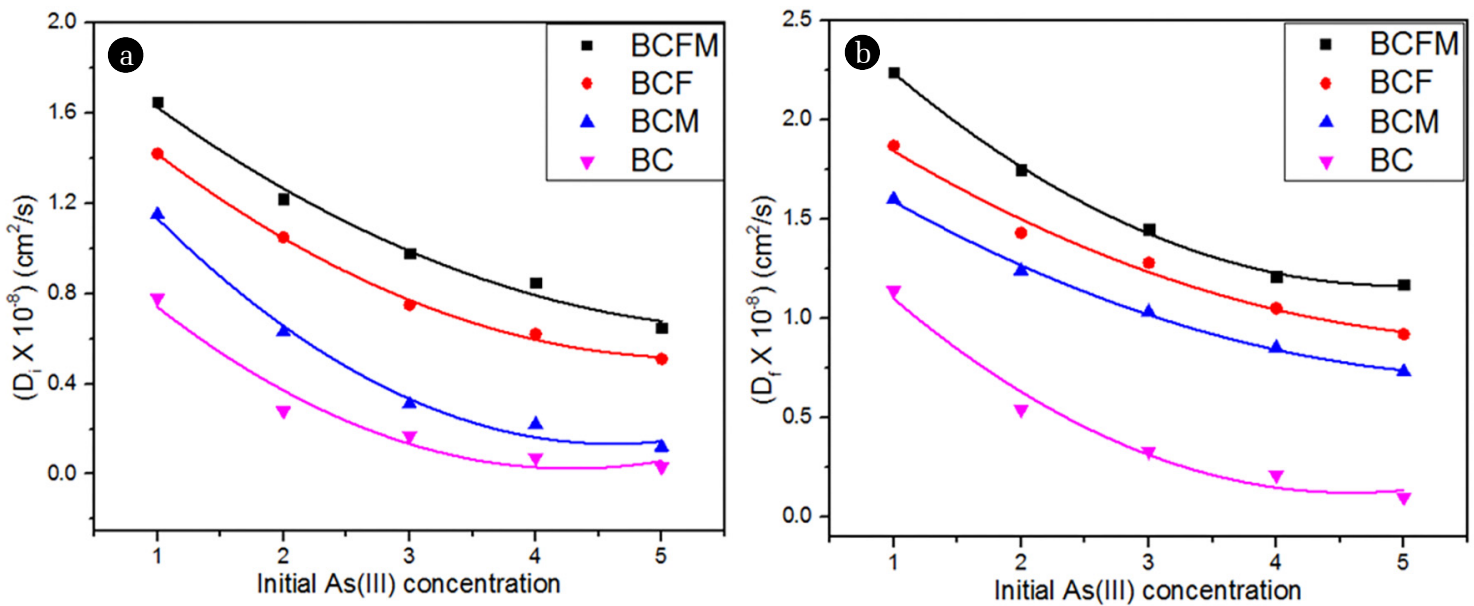

Fig. 2. Influence of (a) Intraparticle diffusivity and (b) film diffusivity on initial As(III) concentration using native and loaded biochar.

$$
D_{i}=0.94 C_{o}^{-1.91} \text { for BC }
$$

In order to test the consistency of the experimental data, plot of $[-0.4977-\ln (1-F)]$ versus $t$ has been shown in Fig. S5(a). It was seen that the plots did not pass through origin indicating that sorption of As(III) is also limited by film diffusion resistance. The calculated diffusivity values $\left(D_{f}\right)$ were in the range of $10^{-7}$ $-10^{-9} \mathrm{~cm}^{2} / \mathrm{s}$ irrespective of the biochar used. This indicated the possibility of film diffusion besides intraparticle diffusion (based on $D_{f}$ values) $[49,50]$. The empirical correlation between $D_{f}$ and $C_{o}$ obtained from Fig. 2(b) are represented in Eqs (28) - (31):

$$
\begin{array}{ll}
D_{f}=2.28 C_{o}^{-0.43} & \text { for BCFM } \\
D_{f}=1.91 C_{o}^{-0.21} & \text { for BCF } \\
D_{f}=1.66 C_{o}^{-0.48} & \text { for BCM } \\
D_{i}=1.27 C_{o}^{-1.31} & \text { for BC }
\end{array}
$$

The McKay et al. [51] mass transfer plots at various initial As(III) concentrations have been shown in Fig. S5(b). It was observed that the values of $\beta_{L}$ decreased with increase in initial As(III) concentration. The values for $\beta_{L}$ showed that velocity of the As(III) ions to migrate from the bulk liquid phase to the solid adsorbent's surface. The obtained mass transfer coefficients $\left(\beta_{\mathrm{L}}\right)$ from this model were $1.5 \times 10^{-5}, 1.3 \times 10^{-5}, 1.2 \times 10^{-5}$ and $0.9 \times 10^{-5} \mathrm{~cm}^{2} / \mathrm{s}$ for BCFM, BCF, BCM and BC respectively, which were observed to be higher than those evaluated from the Boyd model. This showed that the ease of migration of $\mathrm{As}(\mathrm{III})$ ions from the bulk adsorbate to the surface of the adsorbent was quite rapid and thus cannot be inferred as the rate controlling step towards As(III) ions adsorption. Thus, based on mass transfer studies, it can be inferred that adsorptive transport of As(III) ions was dominated by film diffusion at the onset followed by intraparticle diffusion. The probable diffusion mechanism is shown in Fig. 3(a).

\subsubsection{Adsorption thermodynamics}

The thermodynamic parameters $\left(\Delta G^{\circ}, \Delta H\right.$ and $\left.\Delta S\right)$ at four different temperatures ( $298 K, 303 K, 308 K$ and $313 K$ ) have been tabulated in Table 2. The Gibb's free energy change $\left(\Delta G^{\circ}\right)$ dictates the sponta-
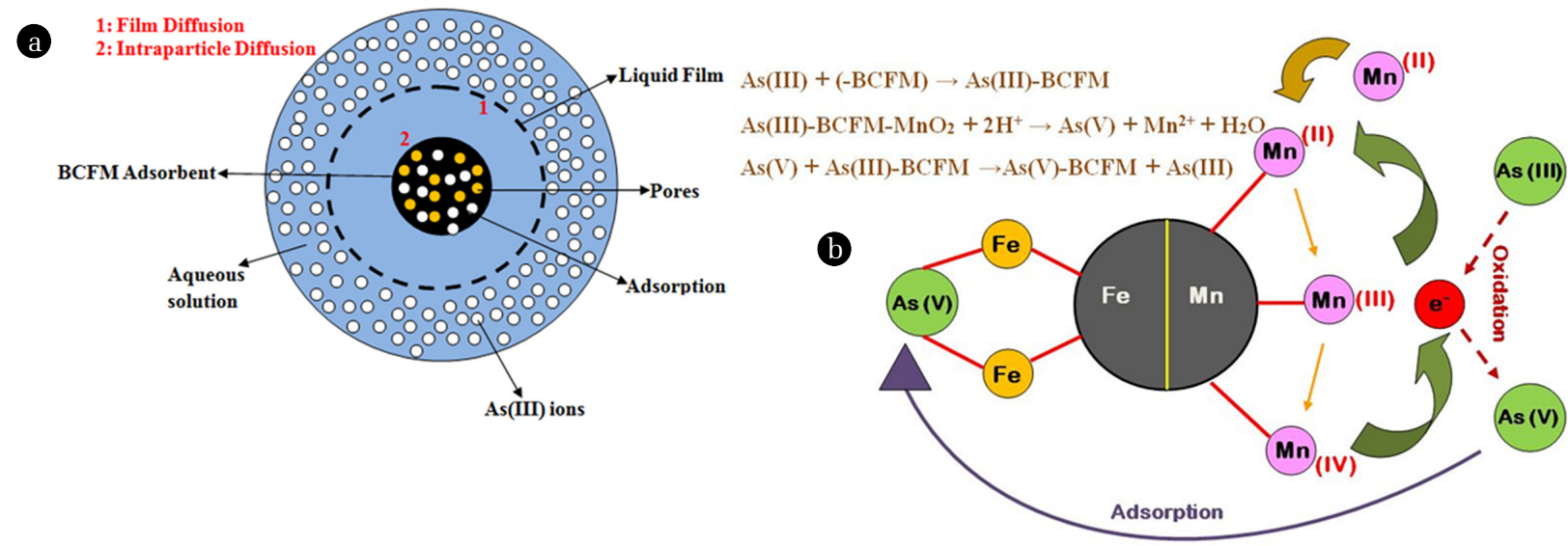

Fig. 3. (a) Diffusion mechanism and (b) Proposed As(III) adsorption mechanism using BCFM adsorbent 
Table 2. Estimated Thermodynamic Parameters for As(III) Adsorption Using Native and Loaded Biochar

\begin{tabular}{|c|c|c|c|c|c|c|}
\hline \multirow{2}{*}{ Adsorbents } & \multicolumn{4}{|c|}{$\Delta G^{\circ}(\mathrm{kJ} / \mathrm{mol})$} & \multirow{2}{*}{$\Delta H(k J / m o l)$} & \multirow{2}{*}{$\Delta S(J / m o l . K)$} \\
\hline & $298 K$ & $303 \mathrm{~K}$ & $308 \mathrm{~K}$ & $313 \mathrm{~K}$ & & \\
\hline BCFM & -2.04 & -1.93 & -1.86 & -1.54 & 6.72 & 40.33 \\
\hline $\mathrm{BCF}$ & -1.98 & -1.89 & -1.69 & -1.45 & 4.84 & 30.56 \\
\hline $\mathrm{BCM}$ & -1.91 & -1.78 & -1.54 & -1.32 & 3.83 & 25.35 \\
\hline $\mathrm{BC}$ & -1.76 & -1.61 & -1.46 & -1.22 & 2.43 & 19.87 \\
\hline
\end{tabular}

neity of adsorption. From Table 2, it can be inferred that the As(III) ions adsorption using native and oxide loaded biochar was feasible and spontaneous at all temperatures (negative $\Delta G^{\circ}$ ). Moreover, the values were observed to increase with rise in temperature suggesting that adsorption of $\mathrm{As}(\mathrm{III})$ was favoured at low temperature. Assimilation or intake of energy due to adsorption of As(III) ions over native and loaded biochar was ascertained from the positive values of $\Delta H$ at all temperatures thus indicating endothermic adsorption of As(III) ions using native and loaded biochar. Positive $\Delta S$ values inferred that there was increase in the randomness of the system due to adsorption of As(III) ions which were said to be less ordered than that in the adsorbate (bulk) solution and thus reflected the adsorbent's affinity towards As(III) ions. Based on the above inferences, it may be said that biochar loaded with both Fe-Mn oxides (BCFM) would function as the best adsorbent at low temperature $(298 K)$ for $\mathrm{As}(\mathrm{III})$ ions removal from water.

\subsection{Column Studies}

Column studies were performed using the biochar loaded with both Fe-Mn oxides (BCFM) as it exhibited maximum adsorption capacity.

\subsubsection{Effect of bed height}

The obtained breakthrough curves for initial As(III) concentration of $1 \mathrm{mg} / \mathrm{L}$ at a constant volumetric flow rate of $7.5 \mathrm{~mL} / \mathrm{min}$ at different bed heights has been shown in Fig. 4(a). The results clearly showed that the treated volume increased with the breakthrough time (Table S4). The breakthrough time increased with the bed depth. As a result of which, the adsorbed amount of As(III) ions, removal percentage and exhaustion time (corresponding to the effluent concentration $=95 \%$ of the initial As(III) concentration) increased proportionally with bed depth. This may be probably due to increase in the number of binding sites per unit volume of the bed. The increase in the amount of adsorbed As(III) ions with increase in bed height was probably due to increase in the quantity of the adsorbent in larger bed depth which in turn provided greater number of binding sites for As(III) ions adsorption. Better intraparticle diffusion was aided by larger breakthrough time [52, 53].

\subsubsection{Effect of Influent flow rate}

The effect of flow rate on the breakthrough time has been studied by varying the influent flow rate from $5 \mathrm{~mL} / \mathrm{min}$ to $10 \mathrm{~mL} / \mathrm{min}$ at a constant bed height of $10 \mathrm{~cm}$ and $1 \mathrm{mg} / \mathrm{L}$ as the initial $\mathrm{As}(\mathrm{III})$ ions concentration. The normalised plots have been presented in Fig. 4(b) and the corresponding parameters in Table S4. It was observed that with increase in influent flow rate, the treated volume decreased thereby reducing the bed service time. Decrease in the residence time of the influent As(III) ions within the bed at higher flow rates may be one of the possible reason. It was evident from the plot that higher the influent flow rate, sharper is the breakthrough curve and longer is the exhaustion time. Reduction in the residence time of the adsorbate molecules caused a poor liquid distribution inside the bed which in turn decreased the diffusion of solute molecules with the adsorbent pores. Thus the adsorption capacity of As(III) ions and breakthrough time reduced with increasing the influent flow rate. Te et al. [54], who studied the adsorption of As(III) ions onto iron mixed mesoporous pellets also inferred that the rate of adsorption increased with increase in the sorbate residence time within the bed indicating the control of the adsorption capacity via mass transfer between the adsorbent and the adsorbate molecules. Similar results have been shown by the authors Nikić et al. [52] for As(III) sorption using Fe-Mn modified granular activated carbon where the sorption capacity decreased with rise in influent flow rate.
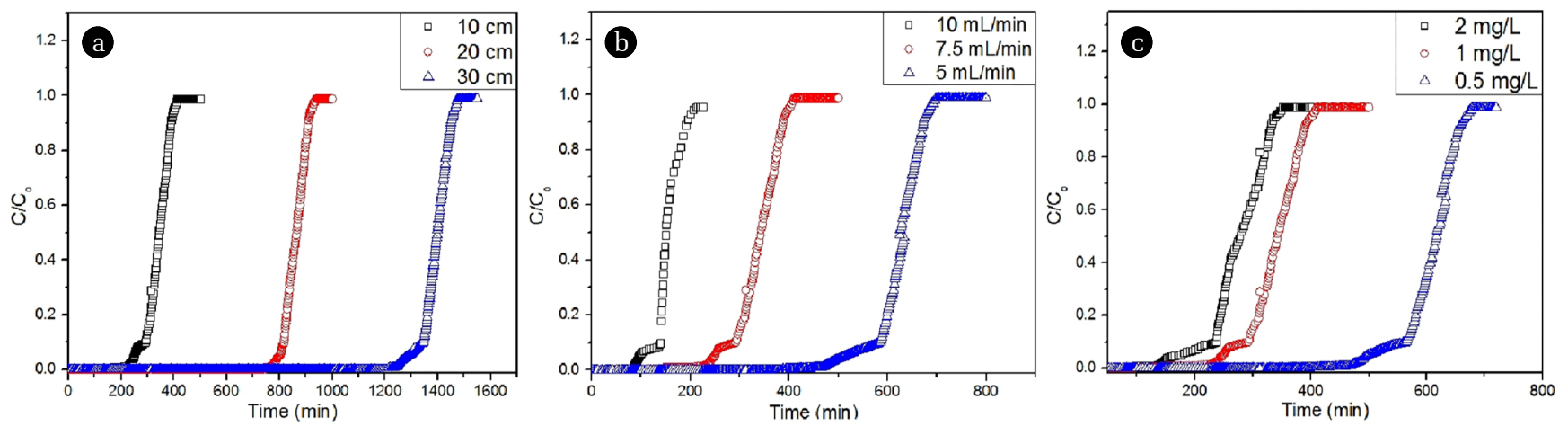

Fig. 4. Breakthrough curves for As(III) ions adsorption at different operating parameters (a) bed height; (b) flow rate; (c) initial concentration. 


\subsubsection{Effect of initial As(III) ions concentration}

The adsorption capacity of As(III) ions at different initial concentration $(0.5-2 \mathrm{mg} / \mathrm{L})$ at a bed depth of $10 \mathrm{~cm}$ and $7.5 \mathrm{~mL} / \mathrm{min}$ as the volumetric flow rate has been shown in Fig. 4(c). It can be observed that the effluent volume before the breakthrough decreased with increase in initial As(III) ions concentration (Table S4). This was probably due to the fact that bed saturation occurred rapidly at high adsorbate concentration thereby reducing the breakthrough time. It can be seen from Table S4 that the total As(III) ions adsorbed increased from $27.98 \mathrm{mg}$ to $30.89 \mathrm{mg}$ with rise in initial As(III) concentration from $0.5 \mathrm{mg} / \mathrm{L}$ to $2.0 \mathrm{mg} / \mathrm{L}$. This was in contrary to the As(III) ions removal percentages which decreased from $80.32 \%$ to $63.55 \%$. The driving force for adsorption is the presence of concentration gradient between the solute molecules in the bulk solution and the presence of vacant sites on the adsorbent's surface. This resulted in the increase in the amount of As(III) ions adsorbed at higher feed concentrations with reduction in removal percentage. As(III) removal using chitosan resulted in decline in adsorption capacity by $28 \%$ with increase in initial concentration from $30-60 \mathrm{mg} / \mathrm{L}$ by the authors Roby et al. [55]. Similar results have been reported by the authors Te et al. [54] using iron mixed mesoporous pellet where the As(III) adsorption capacity was almost independent of the influent concentration. Thus higher feed concentration led to decrease in removal percentage with constant adsorption capacities. Similar results have been reported by Ociński et al. [56], using polymer beads for As(III) removal, the removal percentage declined by around $15 \%$ on doubling the sorbate concentration.

\subsubsection{Breakthrough curve modelling}

The predicted model parameters from Adams-Bohart model have been presented in Table 3. It is observed that the maximum As(III) adsorption capacity $\left(N_{o}\right)$ increased with increase in initial As(III) ions concentration and decreased with increase in flow rate and bed height. Moreover the kinetic rate constant $\left(k_{A B}\right)$ decreased with increase in initial As(III) ions concentration and increased with increase in influent flow rate. This suggested that the system was dominated by external mass transfer resistance. Under such circumstances, the best column performance (minimum mass transfer resistance and high saturation limit) would be governed by high influent $\mathrm{As}(\mathrm{III})$ ions concentration and low flow rate.

Estimated values of bed depth $(x)$ and the corresponding service time $(t)$ in terms of BDST curve are shown in Fig. S6 for an influent concentration of $1 \mathrm{mg} / \mathrm{L}$. The model parameters $K$ and $N_{o}$ obtained from the intercept $(b)$ and slope $(a)$ of the BDST model have been summarised in Table S5. The respective equations for these lines are represented in Eqs. (32) and (33):

$$
\begin{aligned}
& t=50 x+236.67 \text { for } 0.5 \% \text { saturation } \\
& t=52.5 x+16.67 \text { for } 90 \% \text { saturation }
\end{aligned}
$$

From the slope values, it was evident that the two lines were almost parallel to each other and the distance between them was found out to be $4.41 \mathrm{~cm}$. This distance was referred as the height of exchange zone. From the values of slope and intercept of $0.5 \%$ saturation line, the minimum bed depth $\left(x_{0}\right)$ necessary to produce an effluent concentration $\left(C_{B}=0.03 \mathrm{mg} / \mathrm{L}\right)$, was found to be 4.65 $\mathrm{cm}$. At time $(t)=0$, the minimum bed depth required for column operation would be around $4.7 \mathrm{~cm}$ such that outlet concentration of As(III) ions was always less than $0.03 \mathrm{mg} / \mathrm{L}$ (breakthrough concentration). Thus, if a column is operated below this value, the efficiency of the column would be minimum.

The predicted model parameters from Thomas model have been shown in Table 3. Analysis of the regression coefficient values $\left(R^{2}>0.95\right)$ inferred that this model fitted better than the Adams-Bohart kinetic model. It was observed from the table that the maximum adsorption capacity of As(III) ions $\left(q_{o}\right)$ increased with initial As(III) concentration while kinetic rate constant $\left(k_{T H}\right)$ exhibited opposite trend. Besides, with increase in influent flow rate, the rate constant increased and As(III) ions adsorption capacity decreased. Thus the adsorption of As(III) ions onto BCFM adsorbent in fixed column was limited by external mass transfer. Table 4 shows the comparative evaluation of the various forms of metal oxides reported in literature for As(III) adsorption.

\subsubsection{Mass transfer analysis}

The mass transfer coefficient in a fixed bed adsorption depends on the type of flow and its variation with Reynold's number is shown in Fig. S7. It can be seen that with increase in flow rate (Reynold's number), increase in $K_{c}$ was observed. This may be attributed to increase in mass transfer resistance which in turn caused poor distribution of fluid within the bed at high flow rates thereby decreasing the residence time. Based on the linearity of the plot, the generalized empirical relation between $K_{c}$ and $R e$ (Reynold's number) was established in the form of Eq. (34):

\begin{tabular}{|c|c|c|c|c|c|c|c|c|}
\hline \multirow{2}{*}{$C_{o}(\mathrm{mg} / \mathrm{L})$} & \multirow{2}{*}{$h(\mathrm{~cm})$} & \multirow{2}{*}{$Q(\mathrm{~mL} / \mathrm{min})$} & \multicolumn{3}{|c|}{ Adams-Bohart model } & \multicolumn{3}{|c|}{ Thomas model } \\
\hline & & & $k_{A B}$ (L/mg.min) & $N_{o}(\mathrm{mg} / \mathrm{L})$ & $R^{2}$ & $k_{T H}(m L / m g . m i n)$ & $q_{o}(\mathrm{mg} / \mathrm{g})$ & $R^{2}$ \\
\hline 0.5 & 10 & 7.5 & 0.012 & 182.15 & 0.92 & 9.75 & 0.32 & 0.98 \\
\hline 1 & 10 & 7.5 & 0.013 & 225.25 & 0.91 & 9.42 & 0.35 & 0.98 \\
\hline 2 & 10 & 7.5 & 0.013 & 220.65 & 0.94 & 9.15 & 0.41 & 0.97 \\
\hline 1 & 20 & 7.5 & 0.009 & 212.53 & 0.94 & 8.15 & 0.34 & 0.97 \\
\hline 1 & 30 & 7.5 & 0.012 & 195.48 & 0.95 & 9.35 & 0.36 & 0.98 \\
\hline 1 & 10 & 5 & 0.011 & 235.47 & 0.92 & 7.53 & 0.32 & 0.97 \\
\hline 1 & 10 & 10 & 0.022 & 120.69 & 0.93 & 17.15 & 0.23 & 0.99 \\
\hline
\end{tabular}

Table 3. Predicted Model Parameters for As(III) Adsorption Using the Two Models at Different Process Parameters 
Table 4. Comparative Evaluation of the Various Forms of Metal Oxides Used for As(III) Removal

\begin{tabular}{|c|c|c|c|c|c|c|c|}
\hline Adsorbents used & $\begin{array}{l}\text { As(III) sorption } \\
\text { capacity }(\mathrm{mg} / \mathrm{g})\end{array}$ & $\begin{array}{l}\text { Influent flow } \\
\text { rate (mL/min) }\end{array}$ & $\begin{array}{l}\text { Bed Height } \\
(\mathrm{cm})\end{array}$ & $\begin{array}{c}\text { Initial As(II) } \\
\text { concentration } \\
\text { (mg/L) }\end{array}$ & Adsorbate pH & $\begin{array}{l}\text { Breakthrough } \\
\text { models }\end{array}$ & References \\
\hline $\begin{array}{l}\mathrm{Fe} / \mathrm{Mn} \text { entrapped } \\
\text { polymer beads }\end{array}$ & 26.2 & 6.0 & 7.5 & 5.0 & 4.5 & Adams-Bohart & Ociński et al [45] \\
\hline $\begin{array}{l}\text { Iron oxide mixed } \\
\text { mesoporous pellet }\end{array}$ & 0.66 & 12.5 & 5.0 & 2.0 & 7.0 & $\begin{array}{l}\text { Adams-Bohart, } \\
\text { Thomas }\end{array}$ & Te et al. [43] \\
\hline $\begin{array}{l}\text { Granular activated } \\
\text { carbon modified with } \\
\text { Fe-Mn }\end{array}$ & 22.5 & 6.0 & 30.0 & 0.12 & 7.0 & Thomas & Nikić et al. [41] \\
\hline Fe-oxide mixed clay & 0.39 & 12.5 & 5.0 & 1.0 & 7.0 & Thomas & Thanh et al. [49] \\
\hline $\begin{array}{l}\text { Polyvinyl alcohol } \\
\text { stabilized granular } \\
\text { Fe-Mn oxides }\end{array}$ & 3.63 & - & 25.5 & 0.23 & 7.3 & - & Zhang et al. [50] \\
\hline $\begin{array}{l}\text { Biochar loaded Fe-Mn } \\
\text { oxides }\end{array}$ & 28.8 & 7.5 & 10.0 & 1.0 & 7.0 & $\begin{array}{l}\text { Adams-Bohart } \\
\text { Thomas }\end{array}$ & This study \\
\hline
\end{tabular}

$$
K_{c}=0.072(R e)^{1.35}
$$

Thus for a fully operated bed, the flow rate adversely affects the mass transfer coefficients. Therefore, for industrial purposes, the beds are designed in order to have a maximum breakthrough time which in turn decreases the length of mass transfer zone and flow resistances however, increases the residence time distribution within the bed.

\subsection{Proposed As(III) Removal Mechanism}

The adsorption of As(III) through BCF adsorbent took place via mechanism of ligand exchange. The loaded iron present in the biochar coordinated with the hydroxyl radicals from the neutral water solution. This exchange took place by involving ligand exchange group (hydroxyl ions) from the aqueous solution present in Fe-coordinated sphere. Thus the adsorption of As(III) ions using $\mathrm{BCF}$ adsorbent probably took place via release of such hydroxyl groups from the coordinated complexes [57]. While, As(III) adsorption using BCM adsorbent might took place via oxidation (As(III) to $\mathrm{As}(\mathrm{V})$ ) or ligand exchange (hydroxyl ions) reaction between $\mathrm{Mn}$ and arsenite [58]. However, the exact structure of Mn-As species and its removal mechanism needs to be further investigated due to limited literature results. For the pristine biochar adsorbent (BC), the adsorption of As(III) took place mainly by ion exchange process i.e. where the hydroxyl groups $(-\mathrm{OH})$ dominates [20]. However, some residual arsenite adsorption might have also taken place by electrostatic attraction and ion exchange of the ester and carboxylic acid groups [59].

The adsorption of As(III) ions over the surface of BCFM can be hypothesised to take place in three steps: (1) surface migration; (2) deprotonation or dissociation of aqueous As(III) ions and (3) charge complexation at the surface [60]. Initially, the As(III) ions were adsorbed on the surface of BCFM, then oxidation of As(III) to $\mathrm{As}(\mathrm{V})$ takes place by the transfer of one or two electrons to the Mn atoms by the adsorbed As(III) molecules as reported by Zhang et al. [61]. Simultaneously, the oxidised As(V) and reduced
Mn species formed could be isolated from the adsorbent's surface into the bulk solution or could be bonded onto the surface of BCFM. The As(V) species thus formed were rapidly adsorbed by the Fe-oxides on the surface of biochar. Due to rapid reduction of solid Mn-oxides to soluble $\mathrm{Mn}^{2+}$ ions, some fraction of $\mathrm{As}(\mathrm{V})$ species could be released into the aqueous solution, but this fraction would be readily re-adsorbed by Fe-oxides [62]. This resulted in the formation of inner sphere complexes through bonding of oxyanions of As(III) and As(V) by replacement of surface hydroxyl groups [63]. These inner sphere complexes formed on the surface of Fe-oxides may be attributed to the bidendate binuclear and monodentate mononuclear inner sphere complexes [64]. The As(III) removal mechanism and the probable reaction mechanism has been demonstrated in Fig. 3(b).

The above proposed mechanism was confirmed from the results obtained from the isotherm modeling. The greater ease of adsorption of As(III) ions using BCFM adsorbent was justified by the maximum $k_{L}(0.28 \mathrm{~L} / \mathrm{mg})$ and $k_{F}(38.91 \mathrm{mg} / \mathrm{g})$ values for the BCFM adsorbent using Langmuir and Freundlich isotherm models respectively. Favourable and chemical nature of adsorption (irrespective of the biochar samples) was confirmed from the values of heterogeneity $(n>1)$ from the Freundlich model. Since the adsorption over BCFM took place via three steps, the values of binding tendencies $\left(A_{T}\right)$ from the Temkin model also showed its maxima at $A_{T}=10.47$ L/g using BCFM adsorbent. Strong affinity towards As(III) adsorption was confirmed from the $E$ value (from the D-R isotherm) which showed its maximum value at $0.92 \mathrm{~kJ} / \mathrm{mol}$ while the native biochar exhibited minimum $E$ value $(0.45 \mathrm{~kJ} / \mathrm{mol})$. Thus from the obtained values of $R^{2}$ and $\chi^{2}$ (from the isotherm models), the relative affinity towards As(III) adsorption mechanism using the synthesised biochar followed the trend of: $\mathrm{BCFM}>\mathrm{BCF}>\mathrm{BCM}>\mathrm{BC}$

\subsection{Regeneration and Reuse of the Adsorbents}

In order to determine the reusability of BCFM, the adsorbent was regenerated using $10 \% \mathrm{NaOH}$ solution. The removal percentage of As(III) ions after 5 consecutive adsorption/regeneration cycles 
is shown in Fig S8. It can be observed that the adsorption percentage decreased with increase in cycle time. However, significant decrease was not observed till the first three cycles for the loaded biochar while after the fourth cycle, there was a significant decrease in the removal percentage. The amount of $\mathrm{Fe}$ and $\mathrm{Mn}$ from the adsorbent after each cycle was observed to be in the range of 0.00-0.04 $\mathrm{mg} / \mathrm{L} \mathrm{Fe}$ and $0.01-0.03 \mathrm{mg} / \mathrm{L} \mathrm{Mn}$. Thus the total amount of Fe and $\mathrm{Mn}$ in the BCFM was assumed to be constant. There was no significant weight loss observed even after the fifth cycle indicating the good mechanical stability of the adsorbent. The synthesised adsorbent can be extensively used in the adsorption of As(III) ions from ground water in the arsenic affected areas in India such as Bihar, West Bengal, some parts of Uttar Pradesh and Assam. It can also be used as an effective adsorbent in various water purification filters and in the design of fixed bed columns. This adsorbent can be used in a pressure swing adsorption system to treat arsenic laden effluents from cement and some pesticides industries which are said to release considerable amount of arsenic $(>1 \mathrm{mg} / \mathrm{L}$ ).

\subsection{Cost Analysis}

Biomass was obtained free of charge. A pyrolysis unit of around $4.75 \mathrm{~L}$ was used to prepare biochar per batch. Approximately 0.5 $\mathrm{kg}$ of biomass was pyrolysed per batch producing $45 \%$ biochar yield and $450 \mathrm{~mL}$ of bio-oil. The power consumption in a pyrolysis unit was around $4.25 \mathrm{~kW}$ or approximately $0.72 \$ / \mathrm{kg}$ of biochar. The average cost of pre-treatment, cleaning and transportation may be approximated as $0.13 \$ / \mathrm{kg}$. However, the cost of pyrolyser is a one-time investment costing around $725 \$$. Thus an amount of $0.86 \$ / \mathrm{kg}$ of biochar may be approximated as its total cost.

The cost of $98 \% \mathrm{FeCl}_{3}$ and $\mathrm{MnCl}_{2}$ is around $6.0 \$ / \mathrm{kg}$ and 11.0 $\$ / k g$ respectively. The approximated cost for preparing $0.5 \mathrm{M} \mathrm{FeCl}_{3}$ and $\mathrm{MnCl}_{2}$ in $1 \mathrm{~L}$ of solution come out to be $0.5 \$$ and $0.7 \$$ respectively. The estimated cost for preparation of $0.5 \mathrm{M} \mathrm{NaOH}$ solution in a litre comes out to be around $0.2 \$$. The optimum dose for $97 \%$ removal was obtained to be $0.6 \mathrm{~g} / \mathrm{L}$ or $0.25 \$$ (inclusive of all pre-treatment and modifications). However, these values were calculated for simulated water which may vary depending upon As(III) concentration in real groundwater.

The biochar isolated from Providencia stuartii for congo red dye removal was reported to cost around $0.92 \$ / \mathrm{kg}$ of the biochar used [65]. The cost of wood based biochar was estimated around $0.5 \$ / \mathrm{kg}$ which was around one-sixth the cost of commercial grade activated carbon [66]. Biochar from Casuarina equisetifolia for removal of methylene blue dye was estimated around $0.9 \$ / \mathrm{kg}$ [67]. Thus, from the above cited literature, it can be observed that the biochar used in the present study is quite comparative with the ones reported in the literature. However, the available literature for cost analysis of various biochar based sorbents is quite limited and hence the study of cost analysis of biochar based adsorbents can be a new area of research.

\section{Conclusions}

Biochar loaded with Fe-Mn binary oxides (BCFM) showed maximum adsorption capacity of $95.7 \mathrm{mg} / \mathrm{g}$ which was higher than those loaded with individual oxides and pristine biochar. Adsorption was predominantly chemisorption via binding through weak Van der Walls forces. Around 2,000 $\mathrm{mL}$ of simulated water containing As(III) ions was treated before breakthrough at a bed depth of $10 \mathrm{~cm}$ using $\mathrm{Fe}-\mathrm{Mn}$ binary oxides loaded biochar. Simultaneous As(III) oxidation by Mn-oxide and adsorption by Fe-oxide was attributed to its removal mechanism. The adsorbent possessed reusability property up to three cycles. Thus, the synthesised biochar loaded with Fe-Mn binary oxides can be used for arsenic remediation from ground water in terms of its reusability and economy. The adsorbent can also be used in the adsorption of other heavy metals (chromium, cadmium and lead) and dye effluents from textile and leather industries.

\section{Acknowledgements}

HS and ADG are thankful to Technical Education Quality Improvement Programme (TEQIP-III) for providing the required funding to carry out the experiments and Centre for Interdisciplinary Research (CIR) of MNNIT Allahabad for allowing us to carry out sample characterizations and MRC department IIT Kanpur for SEM analysis. ERR thanks IHE Delft (The Netherlands) for staff time support to collaborate with researchers from India on this biochar based, water decontamination, research work.

\section{Author Contributions}

A.D.G. (Research Scholar) conducted all the experiments and wrote manuscript draft. B.S.G. (Post Doctoral Researcher) did the sample analysis and characterization including BET analysis. E.R.R. (Senior Lecturer) supervised on the mathematical part of the manuscript. P.C. (Scientist) helped in reviewing and manuscript correction. M.G. (Project Fellow) worked on continuous column studies. H.S. (Assistant Professor) supervised the work, conceptualization and manuscript correction.

\section{References}

1. Guan X, Du J, Meng X, Sun Y, Sun B, Hu Q. Application of titanium dioxide in arsenic removal from water: A review. $J$. Hazard. Mater. 2012;215:1-16.

2. Smedley PL, Kinniburgh DG. A review of the source, behaviour and distribution of arsenic in natural waters. Appl. Geochem. 2002;17:517-568.

3. Qi J, Zhang G, Li H. Efficient removal of arsenic from water using a granular adsorbent: Fe-Mn binary oxide impregnated chitosan bead. Bioresour. Technol. 2015;193:243-249.

4. Li Y, Han Y, Li W, Li Y, Zhang D, Lan Y. Efficient removal of As(III) via simultaneous oxidation and adsorption by magnetic sulfur-doped $\mathrm{Fe}-\mathrm{Cu}-\mathrm{Y}$ trimetal oxide nanoparticles. Environ. Res. 2020;180:108896.

5. Chakraborti D, Singh SK, Rahman MM, Dutta RN, Mukherjee SC, Pati S, Kar PB. Groundwater arsenic contamination in the 
ganga river basin: A future health danger. Int. J. Environ. Res. Public Health. 2018;15:180.

6. Hu X, Ding Z, Zimmerman AR, Wang S, Gao B. Batch and column sorption of arsenic onto iron-impregnated biochar synthesized through hydrolysis. Water Res. 2015;68:206-216.

7. Zuzolo D, Cicchella D, Demetriades A, Birke M, Albanese S, Dinelli E, Lima A, Valera P, Vivo BD. Arsenic: Geochemical distribution and age-related health risk in Italy. Environ. Res. 2020;182:109076.

8. Wen Z, Lu J, Zhang Y, et al. Facile inverse micelle fabrication of magnetic ordered mesoporous iron cerium bimetal oxides with excellent performance for arsenic removal from water. J. Hazard. Mater. 2020;383:121172.

9. Asere TG, Stevens CV, Laing GD. Use of (modified) natural adsorbents for arsenic remediation: A review. Sci. Total Environ. 2019;676:706-720.

10. Bang S, Meng X. A review of Arsenic interactions with ions and iron hydroxides. Environ. Eng. Res. 2004;9:184-192.

11. Nidheesh PV, Singh TSA. Arsenic removal by electrocoagulation process: Recent trends and removal mechanism. Chemosphere 2017;181:418-432.

12. Huling JR, HulingSG, Ludwig R. Enhanced adsorption of arsenic through the oxidative treatment of reduced aquifer solids. Water Res. 2017;123:183-191.

13. Wang S, Gao B, Zimmerman AR, Li Y, Ma L, Harris WG, Migliaccio KW. Removal of arsenic by magnetic biochar prepared from pinewood and natural hematite. Bioresour. Technol. 2015;175:391-395.

14. Luo M, Lin H, He Y, Li B, Dong Y, Wang L. Efficient simultaneous removal of cadmium and arsenic in aqueous solution by titanium-modified ultrasonic biochar. Bioresour. Technol. 2019; 284:333-339.

15. Amen R, Bashir H, Bibi I, et al. A critical review on arsenic removal from water using biochar-based sorbents: The significance of modification and redox reactions. Chem. Eng. J. 2020;396:125195.

16. Hussain M, Imran M, Abbas G, et al. A new biochar from cotton stalks for As (V) removal from aqueous solutions: its improvement with $\mathrm{H}_{3} \mathrm{PO}_{4}$ and $\mathrm{KOH}$. Environ. Geochem. Health. 2019;204

17. Sattar MS, Shakoor MB, Ali S, Rizwan M, Niazi NK, Jilani A. Comparative efficiency of peanut shell and peanut shell biochar for removal of arsenic from water. Environ. Sci. Pollut. Res. 2019;26:18624-18635.

18. Wongrod S, Simon S, Hullebusch ED, Lens PNL, Guibaud G. Changes of sewage sludge digestate-derived biochar properties after chemical treatments and influence on As(III and V) and Cd(II) sorption. Int. Biodeterior. Biodegrad. 2018;135:96-102.

19. Niazi NK, Bibi I, Shahid M, et al. Arsenic removal by Japanese oak wood biochar in aqueous solutions and well water: Investigating arsenic fate using integrated spectroscopic and microscopic techniques. Sci. Total Environ. 2018;621:1642-1651.

20. Niazi NK, Bibi I, Shahid M, et al. Arsenic removal by perilla leaf biochar in aqueous solutions and groundwater: An integrated spectroscopic and microscopic examination. Environ. Pollut. 2018;232:31-41.

21. Alam MA, Shaikh WA, Alam MO, et al. Adsorption of As (III) and As (V) from aqueous solution by modified Cassia fistula (golden shower) biochar. Appl. Water Sci. 2018;8:198.

22. Luo M, Lin H, He Y, Li B, Dong Y, Wang L. Efficient simultaneous removal of cadmium and arsenic in aqueous solution by titanium-modified ultrasonic biochar. Bioresour. Technol. 2019; 284:333-339.

23. Vithanage M, Herath I, Joseph S, et al. Interaction of arsenic with biochar in soil and water: A critical review. Carbon 2017;113:219-230.

24. Xia D, Tan F, Zhang C, et al. $\mathrm{ZnCl}_{2}$-activated biochar from biogas residue facilitates aqueous As(III) removal. Appl. Surf. Sci. 2016;377:361-369.

25. Zhu N, Yan T, Qiao J, Cao H. Adsorption of arsenic, phosphorus and chromium by bismuth impregnated biochar: Adsorption mechanism and depleted adsorbent utilization. Chemosphere 2016;164:32-40.

26. Lin L, Qiu W, Wang D, Huang Q, Song Z, Chau HW. Arsenic removal in aqueous solution by a novel Fe-Mn modified biochar composite: Characterization and mechanism. Ecotoxicol. Environ. Saf. 2017;144:514-521.

27. Jung YJ, Kamimoto Y. Arsenic removal properties by electrolyzed and calcined manganese dioxide. Environ. Eng. Res. 2020;25:735-741.

28. Sarkar S, Guibal E, Quignard F, SenGupta A. Polymer-supported metals and metal oxide nanoparticles: Synthesis, characterization, and applications. J. Nanoparticle Res. 2012;14:715.

29. Liang M, Xu S, Zhu Y, et al. Preparation and characterization of fe-mn binary oxide/mulberry stem biochar composite adsorbent and adsorption of $\mathrm{Cr}(\mathrm{VI})$ from aqueous solution. Int. J. Environ. Res. Public Health. 2020;17:676.

30. Tchounwoun PB, Yedjou CG, Patlolla AK, Sutton DJ. Heavy Metal Toxicity and the Environment. Mol. Clin. Environ. Toxicol. 2012;120:133-164.

31. Pillai A, Sunita G, Gupta VK. A new system for the spectrophotometric determination of arsenic in environmental and biological samples. Anal. Chim. Acta. 2000;408:111-115.

32. McKay G, Otterburn MS, Aga JA. Intraparticle diffusion process occurring during adsorption of dyestuffs. Water. Air. Soil Pollut. 1987;36:381-390.

33. Gupta KN, Kumar R. Fixed bed utilization for the isolation of xylene vapor: Kinetics and optimization using response surface methodology and artificial neural network. Environ. Eng. Res. 2020;26(2):200105.

34. Patel H. Fixed-bed column adsorption study: a comprehensive review. Appl. Water Sci. 2019;9:45.

35. Rao RAK, Khan MA, Jeon BH. Utilization of carbon derived from mustard oil cake (CMOC) for the removal of bivalent metal ions: Effect of anionic surfactant on the removal and recovery. J. Hazard. Mater. 2010;173:273-282.

36. Xu Y, Xie X, Feng Y, et al. As(III) and As(V) removal mechanisms by Fe-modified biochar characterized using synchrotron-based X-ray absorption spectroscopy and confocal micro-X-ray fluorescence imaging. Bioresour. Technol. 2020;304:122978.

37. Lin L, Song Z, Huang Y, Khan ZH, Qiu W. Removal and Oxidation of Arsenic from Aqueous Solution by Biochar Impregnated with Fe-Mn Oxides. Water. Air. Soil Pollut. 2019;230:105.

38. Nguyen TH, Pham TH, Thi HTN, et al. Synthesis of 
Iron-Modified Biochar Derived from Rice Straw and Its Application to Arsenic Removal. J. Chem. 2019;5295610.

39. An B, Zhao D. Immobilization of As(III) in soil and groundwater using a new class of polysaccharide stabilized Fe-Mn oxide nanoparticles. J. Hazard. Mater. 2012;211:332-341.

40. Zhai S, Li M, Wang D, Zhang L, Yang Y, Fu S. In situ loading metal oxide particles on bio-chars: Reusable materials for efficient removal of methylene blue from wastewater. J. Clean. Prod. 2019;220:460-474.

41. Zhang L, Liu X, Huang X, Wang W, Sun P, Li Y. Adsorption of $\mathrm{Pb}^{2+}$ from aqueous solutions using $\mathrm{Fe}-\mathrm{Mn}$ binary oxides-loaded biochar: kinetics, isotherm and thermodynamic studies. Environ. Technol. 2019;40:1853-1861.

42. Zhang G, Qu J, Liu H, Liu R, Wu R. Preparation and evaluation of a novel Fe-Mn binary oxide adsorbent for effective arsenite removal. Water Res. 2007;41:1921-1928.

43. Ayoob S, Gupta AK, Bhakat PB. Performance evaluation of modified calcined bauxite in the sorptive removal of arsenic(III) from aqueous environment. Colloids Surfaces A Physicochem. Eng. Asp. 2007;293:247-254.

44. Altundoan HS, Altundoan S, Tümen F, Bildik M. Arsenic adsorption from aqueous solutions by activated red mud. Waste Manag. 2002;22:357-363.

45. Bibi S, Farooqi A, Hussain K, Haider N. Evaluation of industrial based adsorbents for simultaneous removal of arsenic and fluoride from drinking water. J. Clean. Prod. 2015;87:882-896.

46. Ghosh S, Prabhakar R, Samadder SR. Performance of $\gamma$ -aluminium oxide nanoparticles for arsenic removal from groundwater. Clean Technol. Environ. Policy. 2019;21:121-138.

47. Singha B, Das SK. Biosorption of Cr(VI) ions from aqueous solutions: Kinetics, equilibrium, thermodynamics and desorption studies. Colloids Surfaces B Biointerfaces. 2011;84: 221-232.

48. Singh TS, Pant KK. Kinetics and mass transfer studies on the adsorption of arsenic onto activated alumina and iron oxide impregnated activated alumina. Water Qual. Res. J. Canada. 2006;41:147-156.

49. Karthikeyan S, Sivakumar B, Sivakumar N. Film and Pore Diffusion Modeling for Adsorption of Reactive Red 2 from Aqueous Solution on to Activated Carbon Preparedfrom Bio-Diesel Industrial Waste. E-Journal Chem. 2012;7:1-10.

50. Doke KM, Khan EM. Equilibrium, kinetic and diffusion mechanism of $\mathrm{Cr}(\mathrm{VI})$ adsorption onto activated carbon derived from wood apple shell. Arab. J. Chem. 2017;10:252-260.

51. Fu D, Zhang Y, Lv F, Chu PK. Shang J. Removal of organic materials from TNT red water by Bamboo Charcoal adsorption. Chem. Eng. J. .2012;193:39-49.

52. Nikić J, Agbaba J, Watson MA, Tubić A, Šolić M, Maletić S, Dalmacija B. Arsenic adsorption on Fe-Mn modified granular activated carbon (GAC-FeMn): batch and fixed-bed column studies. J. Environ. Sci. Heal. - Part A Toxic/Hazardous Subst. Environ. Eng. 2019;54:168-178.

53. Ociński D, Mazur P. Highly efficient arsenic sorbent based on residual from water deironing - Sorption mechanisms and col- umn studies. J. Hazard. Mater. 2020;382:121062.

54. Te B, Wichitsathian B, Yossapol C, Wonglertarak W. Investigation of Arsenic Removal from Water by Iron-Mixed Mesoporous Pellet in a Continuous Fixed-Bed Column Water. Air. Soil Pollut. 2018;229:296.

55. Roby RB, Gagnon J, Deschênes JS, Chabot B. Investigation of fixed bed adsorption column operation parameters using a chitosan material for treatment of arsenate contaminated water. J. Environ. Chem. Eng. 2018;6:505-511.

56. Ociński D, Sobala IJ, Balawejder EK. Freeze-drying as the post-processing technique improving adsorptive properties of waste $\mathrm{Fe} / \mathrm{Mn}$ oxides entrapped in polymer beads towards As(III) and As(V). Sep. Sci. Technol. 2020;55:487-500.

57. Joshi S, Sharma S, Kumari A, Shreshtha S, Shreshtha B. Arsenic Removal from Water by Adsorption onto Iron Oxide/NanoPorous Carbon Magnetic Composite. Appl. Sci. 2019;9:3732.

58. Zhu N, Yan T, Qiao J, Cao H. Synthesis of Manganese Chloride Activated Carbon Deriving from Wheat Straw and its Adsorption Mechanism for Arsenic and Chromium. J. Environ. Anal. Chem. 2016;3:172.

59. Li H, Dong X, da Silva EB, de Oliveira LM, Chen Y, Ma LQ. Mechansims of metal sorption by biochars: Biochar characteristics and modifications. Chemosphere. 2017;178:466-478.

60. Kong S, Wang Y, Zhan $\mathrm{H}$, Yuan S, Yu M, Liu M. Adsorption/Oxidation of Arsenic in Groundwater by Nanoscale Fe-Mn Binary Oxides Loaded on Zeolite. Water Environ. Res. 2014;86:147-155.

61. Zhang W, Zhang G, Liu C, et al. Enhanced removal of arsenite and arsenate by a multifunctional Fe-Ti-Mn composite oxide: Photooxidation, oxidation and adsorption. Water Res. 2018;147:264-275.

62. Zhang W, Liu C, Wang L, et al. A novel nanostructured Fe-Ti-Mn composite oxide for highly efficient arsenic removal: Preparation and performance evaluation. Colloids Surfaces A Physicochem. Eng. Asp. 2019;561:364-372.

63. Thanh NC, Wichitsathian B, Yossapol C, Wonglertarak W, Te B. Improvement of aqueous solution coexisting with arsenite and arsenate using iron mixed porous clay pellets in batch and fixed-bed column studies. Water Sci. Technol. Water Supply. 2019;19:1927-1937.

64. Zhang G, Luo J, Wang L, Zhang X. Polyvinyl alcohol-stabilized granular Fe-Mn binary oxide as an effective adsorbent for simultaneous removal of arsenate and arsenite. Environ. Technol. 2019;1575479.

65. Goswami M, Chaturvedi P, Sonwani RK, et al. Application of Arjuna (Terminalia arjuna) seed biochar in hybrid treatment system for the bioremediation of Congo red dye. Bioresour. Technol. 2020;307:123203.

66. Galinato SP, Yoder JK, Granatstein D. The economic value of biochar in crop production and carbon sequestration. Energy Policy. 2011;39:6344-6350

67. Bharti V, Vikrant K, Goswami M, et al. Biodegradation of methylene blue dye in a batch and continuous mode using biochar as packing media. Environ. Res. 2019;171:356-364. 